\section{First Nations children}

The editorial "Every child deserves a home" does not mention that First Nations children are six to eight times more likely to be in child welfare care. The factors driving the over-representation of First Nations children in care (poverty, poor housing, substance misuse by caregivers) are responsive to services, but equitable funding is needed to address the problem. ${ }^{2}$ There is growing evidence that successful adoption placements must fully respect a child's cultural and linguistic identity. Despite this, the federal government provides no funding to First Nations on reserve for adoption programs, even though pilot adoption programs created by First Nations have won numerous international awards of excellence. Residential schools have closed, but sadly, many of the federal government's policies undermining First Nations children continue to flourish.

\section{Cindy Blackstock MM PhD}

Executive Director, First Nations Child and Family Caring Society of Canada, Ottawa, Ont.

\section{REFERENCES}

1. Eggertson L, MacDonald N, Baldassi CL, et al. Every child deserves a home. CMAJ 2009;181: E265-6.

2. Trocmé N, Knoke D, Blackstock C. Pathways to the overrepresentation of Aboriginal children in Canada's child welfare system. Soc Serv Rev 2004;78:577-600

For the full letter, go to: www.cmaj.ca/cgi/eletters /181/12/E265\#261906

DOI:10.1503/cmaj.110-2029

\section{Anti-IL-5 therapy and DRESS}

The phenomenon of drug rash, eosinophilia, systemic symptoms (DRESS) described in the case report by De Greef and colleagues ${ }^{1}$ is most likely the result of cellular apoptosis due to excessive cytokines and mediators released by drug-specific T-cells. ${ }^{2}$ Raised levels of interleukin-4 (IL-4), IL-5 and IL-13 have been reported in patients, and because these cytokines are responsible for maturation and differentiation of eosinophils, they explain the eosinophilia seen in this condition. ${ }^{2}$ Mediators released due to eosinophil degranulation, such as eosinophilderived neurotoxin and major basic protein, activate and degranulate mast cells; subsequent histamine release can perpetuate the reaction. DRESS is known to cause serious end-organ damage, which raises the question of whether specific cytokine-directed therapy is likely to be beneficial in these patients. Only a well-designed clinical trial can answer this question.

\section{Sujoy Khan MRCP}

Path Links Immunology, Scunthorpe General Hospital, Scunthorpe, UK

\section{REFERENCES}

1. De Greef E, Mennie K, Muise A. Drug reaction with eosinophilia and systemic symptoms. CMAJ 2010;182: 481 .

2. Beeler A, Engler O, Gerber BO, et al. Long-lasting reactivity and high frequency of drug-specific $\mathrm{T}$ cells after severe systemic drug hypersensitivity reactions. J Allergy Clin Immunol 2006;117:455462

For the full letter, go to: www.cmaj.ca/cgi/eletters /182/5/481\#316124

DOI:10.1503/cmaj.110-2054

\section{Sleeping nets and dengue}

The article "Dengue fever on the rise at tourist getaways" recommends the use of bed nets to reduce the incidence of dengue. However, dengue is transmitted by day-active mosquitoes, with significantly high peak periods of activity in the early morning and, especially, early to late evening. Thus, for many travellers to the tropics and subtropics, the most hazardous time with respect to dengue may be at an outside evening meal. I recommend that in dengue-infested areas, diners wear long trousers, shoes and socks to the evening meal and ensure that they've treated their ankles, socks and lower legs or trousers with a good-quality repellent. Long-sleeved shirts will reduce the risk of bites on the arms, and judicious application of repellent to the ears and back of the neck will further reduce risk. Most travellers do not need night-time bed nets unless they are bothered by nocturnally biting mosquitoes or they are in malariaendemic areas (in which case bed nets are essential).

\section{Stephen M. Smith}

Department of Biology, University of Waterloo, Waterloo, Ont.

\section{REFERENCE}

1. Rynor B. Dengue fever on the rise at tourist getaways. CMAJ 2010;182:E195-96.

For the full letter, go to: www.cmaj.ca/cgi/eletters /182/4/E195\#298091

DOI:10.1503/cmaj.110-2046

\section{End of life, continued}

My brief Salon piece, "End of life, year after year after year," obviously touched a nerve with Dr. Wohlgemut. ${ }^{2}$ However, his reply insists on a host of views that I do not hold. I do not suggest that Fred's doctors should have been smarter, or that because physicians are indeed often "such poor predictors of mortality that we should abandon the task." Nor do I doubt, or suggest to the contrary, that pressing on with aggressive therapies is sometimes inadvisable. However, Dr. Wohlgemut and I agree on an essential fact: Physician prognoses are imperfect indicators of longevity and should be understood as such. The tentative nature of prognoses results from the limits of our knowledge, the limits of our diagnostics and the natural variation (physically and socially) among patients. They surprise continually.

\section{Tom Koch PhD}

Bioethicist, Toronto, Ont.

\section{REFERENCES}

1. Koch T. End of life, year after year after year. CMAJ 2009; 181:868.

2. Wohlgemut J. Going gentle. CMAJ 2010;182:412 .

For the full letter, go to: $w w w . c m a j . c a / c g i / e l e t t e r s$ /182/4/412\#311204

DOI:10.1503/cmaj.110-2056 